\title{
Escherichia coli 0121 outbreak associated with raw milk Gouda-like cheese in British Columbia, Canada, 2018
}

\author{
Eva Boyd ${ }^{1 \star}$, Aljosa Trmcic ${ }^{1}$, Marsha Taylor ${ }^{1}$, Sion Shyng ${ }^{1}$, Paul Hasselback², Stephanie Man ${ }^{3}$, \\ Christine Tchao ${ }^{3}$, Jason Stone ${ }^{4}$, Loretta Janz ${ }^{3}$, Linda Hoang ${ }^{1,3,5}$, Eleni Galanis ${ }^{1,6}$
}

\section{Abstract}

Background: In 2018, a Shiga toxin-producing Escherichia coli O121 outbreak that affected seven individuals was associated with raw milk Gouda-like cheese produced in British Columbia, Canada.

Objectives: To describe the E. coli 0121 outbreak investigation and recommend greater control measures for raw milk Gouda-like cheese.

Methods: Cases of E. coli O121 were identified through laboratory testing results and epidemiologic surveillance data. The cases were interviewed on exposures of interest, which were analyzed against Foodbook Report values for British Columbia. Environmental inspection of the dairy plant and the cheese products was conducted to ascertain a source of contamination. Whole genome multi-locus sequence typing (wgMLST) was performed on all positive E. coli O121 clinical and food isolates at the provincial laboratory.

Results: Four out of the seven cases consumed the same raw milk Gouda-like cheese between August and October 2018. The implicated cheese was aged longer than the required minimum of 60 days, and no production deficiencies were noted. One sample of the implicated cheese tested positive for $E$. coli 0121 . The seven clinical isolates and one cheese isolate matched by wgMLST within 6.5 alleles.

Conclusion: Raw milk Gouda and Gouda-like cheese has been implicated in three previous Shiga toxin-producing E. coli outbreaks in North America. It was recommended product labelling to increase consumer awareness and thermization of milk to decrease the risk of illness associated with raw milk Gouda and Gouda-like cheese.
This work is licensed under a Creative Commons Attribution 4.0 International License.

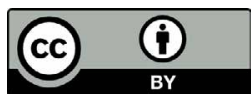

Affiliations

1 British Columbia Centre for Disease Control, Vancouver, BC

${ }^{2}$ Island Health Authority, Victoria, BC

${ }^{3}$ British Columbia Centre for Disease Control Public Health Laboratories, Vancouver, BC

${ }^{4}$ Fraser Health Authority, Surrey, BC

${ }^{5}$ Department of Pathology and Laboratory Medicine, University of British Columbia, Vancouver, BC

${ }^{6}$ School of Population and Public Health, University of British Columbia, Vancouver, BC

\section{${ }^{\star}$ Correspondence:}

evaweingart|@gmail.com

Suggested citation: Boyd E, Trmcic A, Taylor M, Shyng S, Hasselback P, Man S, Tchao C, Stone J, Janz L, Hoang L, Galanis E. Escherichia coli 0121 outbreak associated with raw milk Gouda-like cheese in British Columbia, Canada, 2018. Can Commun Dis Rep 2021;47(1):11-6. https://doi.org/10.14745/ccdr.v47i01a03

Keywords: Escherichia coli O121, raw milk, Gouda, cheese, foodborne, disease outbreak

\section{Introduction}

Shiga toxin-producing Escherichia coli (STEC) is a major cause of foodborne illness in North America. STEC infections cause diarrheal illness and may lead to severe complications, such as hemolytic uremic syndrome, and death $(1,2)$. The incidence rate of 0157 STEC illness has been decreasing, whereas the rate of non-O157 STEC, including 0121 , has been increasing in many countries, likely due to changes in laboratory methods of detection $(3,4)$. Outbreaks of STEC 0121 have been associated with raw flour, fresh or frozen produce, dairy and beef products $(1,5-8)$.
The risk of STEC due to unpasteurized dairy products has been previously described (9-11). Between 2002 and 2013, three E. coli 0157 outbreaks associated with raw milk Gouda cheeses aged for at least 60 days were reported in North America (12-14), including one associated with a British Columbia (BC) dairy plant (13). Following each outbreak, public health professionals recommended strengthening control measures to decrease the risk associated with raw milk Gouda cheeses (12-15). None of these changes had been implemented in Canada by 2018. 
In November 2018, another STEC outbreak associated with a raw milk Gouda-like cheese occurred in BC (population: 5.1 million).

The objective of this article is to describe the outbreak investigation and findings and reiterate the need for greater control measures related to raw milk Gouda-like cheese.

\section{Methods}

Shiga toxin-producing $E$. coli cases are reportable in BC (16). The local health authorities interview all reported cases using a standard surveillance form, collecting demographic, clinical and exposure data for 10 days, equivalent to the maximum incubation period (17).

A confirmed case was defined as a person infected with $E$. coli O121 between August 1, 2018, and November 30, 2018, visiting or residing in $\mathrm{BC}$, with an isolate matching within 10 alleles by whole genome multi-locus sequence typing (wgMLST). A single interviewer used an outbreak questionnaire focusing on dairy, meat and farm exposures to re-interview cases.

We compared case exposures to those of the $\mathrm{BC}$ population using Foodbook Report values (18). Binomial probability was used to calculate the risk of exposure by comparing the observed proportion of cases exposed in the outbreak to the expected proportion of individuals exposed in the BC population. A $p<0.05$ was used to denote statistical significance. Case purchase data were collected using grocery store consumer cards and shopping receipts and reviewed to identify similar products as well as purchase dates and brands. Samples of leftover products were collected from case homes and grocery stores. All case data and exposure information were analyzed using Microsoft Excel.

Investigators inspected the dairy plant that was the source of the outbreak ("dairy plant $A^{\prime \prime}$ ), reviewed records related to cheese production and distribution, collected samples and, in collaboration with local health inspectors, investigated potential sources of contamination and any deficiencies in the manufacturing process. They also determined the product distribution pathways for the implicated cheese.

The BC Ministry of Agriculture supplied information about the condition of the cow herd and results of routine raw milk testing including non-hemolytic E. coli, total bacterial count and somatic cell count using standard automatic testing methods. Cheese testing by dairy plant $A$ was conducted under a mandatory finished product testing program.

Local BC laboratories with positive molecular assays for stx genes submit all the positive samples to the BC Centre for Disease Control (BCCDC) Public Health Laboratory. Other frontline laboratories submit E. coli O157 isolates, bloody stools and/or stools from patients with hemolytic uremic syndrome, according to provincial guidelines, to the Public Health Laboratory for stx 1 and stx2 gene detection and culture (19). All STEC received at, or recovered by, the Public Health Laboratory are routinely serotyped using a gene detection polymerase chain reaction (PCR) targeting the most common serotypes in BC: O26, O45, O111, O103, O121 and O145.

The Public Health Laboratory tested food samples and environmental swabs using an adaptation of published Health Canada Compendium of Analytical Methods for E. coli 0157:H7 (20). The molecular detection of stx 1 and stx2 genes and O-typing was performed in enrichment broth. Positive detection in enrichment broths necessitated subsequent culture isolation. These isolates were then serotyped as described above.

All STEC isolates underwent wgMLST. The wgMLST schema for E. coli compared 17,380 loci in the $E$. coli genome according to standardized procedures used by PulseNet Canada (21). The PulseNet criterion of isolates with 10 or less allele differences was used to define a wgMLST genomic cluster.

\section{Results}

There were seven confirmed cases. The onset dates ranged from August 19 to November 9, 2018 (Figure 1). Six cases resided in Health Region 1 and one in Health Region 2. The median age was 28 years (range: 22-64 years). Five were female. There were no hospitalizations and no deaths were reported.

\section{Figure 1: Confirmed outbreak cases of Escherichia coli 0121 infection by week of illness onset and dates of major outbreak investigations and control actions, British Columbia, 2018}

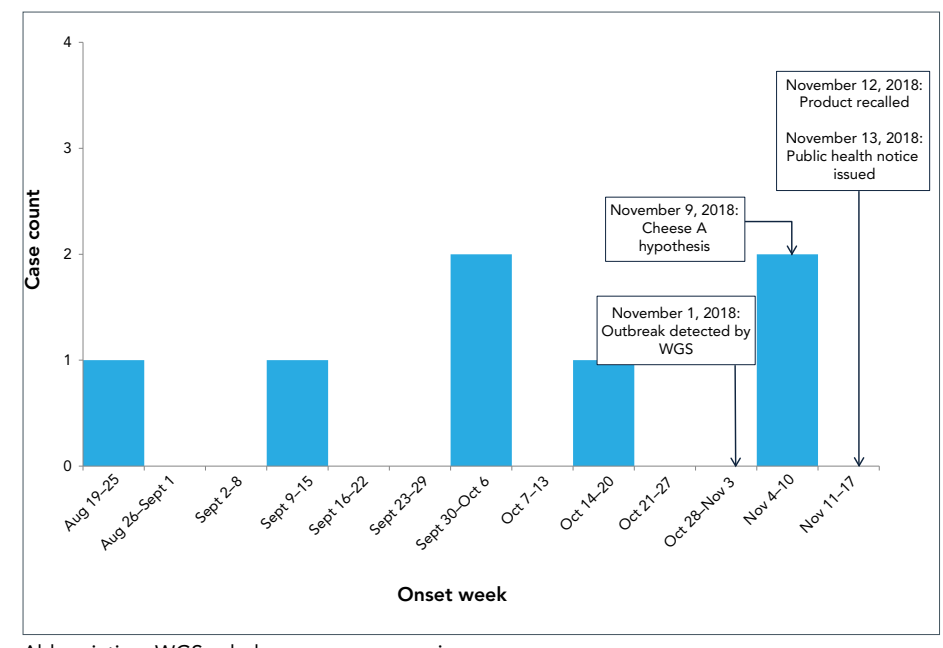

Abbreviation: WGS, whole genome sequencing

Based on initial case interviews, all seven cases reported consuming cheese. No secondary interview information was available for one case. Secondary interviews (conducted with six cases) as well as purchase data (available for two cases) 
identified five cases who consumed a "spicy" or "spiced" cheese from dairy plant $A$, and one case who ate cheese but did not recall eating cheese from dairy plant $A$. Four cases confirmed consuming cheese $A$, a raw milk Gouda-like cheese with added spices that was produced at dairy plant $A$ in Health Region 1. One of the four cases visited dairy plant A in August to September, where they sampled cheese A, and the other three purchased cheese $A$ from three different grocery stores between September and October.

Outbreak cases were significantly more likely to have consumed Gouda or Gouda-like cheese $(p<0.001)$ as well as any unpasteurized cheese $(p<0.001)$ than the healthy BC population (6.3\%, and $0.9 \%$, respectively) (18). Consumption data on raw milk Gouda-like cheese were unavailable for the healthy BC population.

Dairy plant A was a farmstead operation with approximately 45 dairy cows that supplied all the milk for the plant's cheese production. Cheese $A$ was a raw milk washed curd cheese made following a process similar to that used to make Gouda cheese. The curd, obtained after coagulation and cutting, was washed in a mixture of whey and hot water and mixed with a blend of spices that had been boiled in water. Blocks of cheese curd were vacuum-sealed in bags and aged for at least three months. After aging, cheese blocks were cut and packaged onsite for distribution and sale at farmers' markets, grocery stores, restaurants and at the farmgate store.

Routine testing of the farm's raw milk by the Ministry of Agriculture between May and November 2018 found low total bacterial counts, low somatic cell counts and absence of non-hemolytic E. coli. Dairy plant A's product testing of cheese A was in compliance, testing below the detection limit for E. coli. Review of the inspection records revealed no major deficiencies.

Lot traceability from dairy plant $A$ to the distributor and direct accounts was maintained, but lot traceability from the distributor to retail accounts was not maintained. The best-before date on the retail sample package of cheese $A$ that tested positive allowed inspectors to identify the production date as March 31, 2018. This batch was cut on August 1, 7 and 8, 2018. Apart from some pieces that were served onsite to visitors, a single distributor received the entire batch on August 8 and 14, 2018, and distributed it to retail locations throughout $\mathrm{BC}$.

Initial detection of an E. coli O121 stx2 cluster of two clinical cases clustering by wgMLST occurred on October 25, 2018. A third E. coli 0121 case was detected and matched by wgMLST on November 1, 2018. Four additional clinical cases of E. coli O121 stx2 were subsequently identified.

The Public Health Laboratory tested 41 cheese samples from 24 batches between April 27, 2018, and November 2, 2018, as well as three spice samples, one meat sample and 11 environmental samples from dairy plant $A$. Thirty-eight cheese samples were collected from dairy plant $A$, one sample of cheese A was collected from a retailer in Health Region 2, and two unopened packages of different dairy plant A cheese were collected from a case's home. One cheese sample tested positive for stx 2 and two for stx 1 (Table 1). The stx2-positive sample grew E. coli 0121 , whereas the two stx 1 samples were unable to grow. All other samples, including the environmental swabs, tested negative.

Table 1: Results of food and environmental testing, Escherichia coli 0121 outbreak, British Columbia, 2018

\begin{tabular}{|l|l|l|l|}
$\begin{array}{c}\text { Sample type, } \\
\text { production } \\
\text { date }\end{array}$ & \multicolumn{1}{|c|}{$\begin{array}{c}\text { Sample } \\
\text { location }\end{array}$} & $\begin{array}{c}\text { Shiga toxin } \\
\text { result }\end{array}$ & \multicolumn{1}{|c|}{$\begin{array}{c}\text { Culture } \\
\text { result, } \\
\text { serotype }\end{array}$} \\
\hline $\begin{array}{l}\text { Cheese A, } \\
\text { March 31, 2018 }\end{array}$ & Retail & Positive; stx2 & E. coli, O121 \\
\hline $\begin{array}{l}\text { Cheese A, } \\
\text { April 27, 2018 }\end{array}$ & Dairy plant A & Positive; stx1 & $\begin{array}{l}\text { Unable to } \\
\text { isolate }\end{array}$ \\
\hline $\begin{array}{l}\text { Cheese A, } \\
\text { August 3, 2018 }\end{array}$ & Dairy plant A & Positive; stx1 & $\begin{array}{l}\text { Unable to } \\
\text { isolate }\end{array}$ \\
\hline $\begin{array}{l}\text { Non-cheese A } \\
\text { sample (n=2) }\end{array}$ & Case home & Negative & N/A \\
\hline $\begin{array}{l}\text { Environmental } \\
\text { swabs ( } n=11)^{\mathrm{a}}\end{array}$ & Dairy plant A & Negative & N/A \\
\hline $\begin{array}{l}\text { Other foods } \\
(n=40)^{b}\end{array}$ & Dairy plant A & Negative & N/A \\
\hline
\end{tabular}

Abbreviation: N/A: not applicable

a Environmental swabs included four swabs of vat pasteurizer outlet valve, two swabs of raw milk line, two swabs of aging room wall and lights, two swabs of raw milk pump and a filter sock used in the raw milk tank

b Other foods: cheese wheels of cheese $A(n=17)$, cheese wheels of other cheese types $(n=19)$, spice mixes $(n=3)$, meat sample $(n=1)$

All clinical and food isolates clustered by wgMLST within 0 to 6.5 alleles (Figure 2). The stx2-positive cheese isolate clustered within one allele of the nearest clinical isolate and by six alleles of all clinical isolates within the outbreak. The next closest STEC isolate in the PulseNet Canada database was 45 alleles different from the closest isolate in the outbreak.

Figure 2: Phylogenetic tree of Escherichia coli 0121 outbreak cases and cheese A sample, British Columbia, 2018

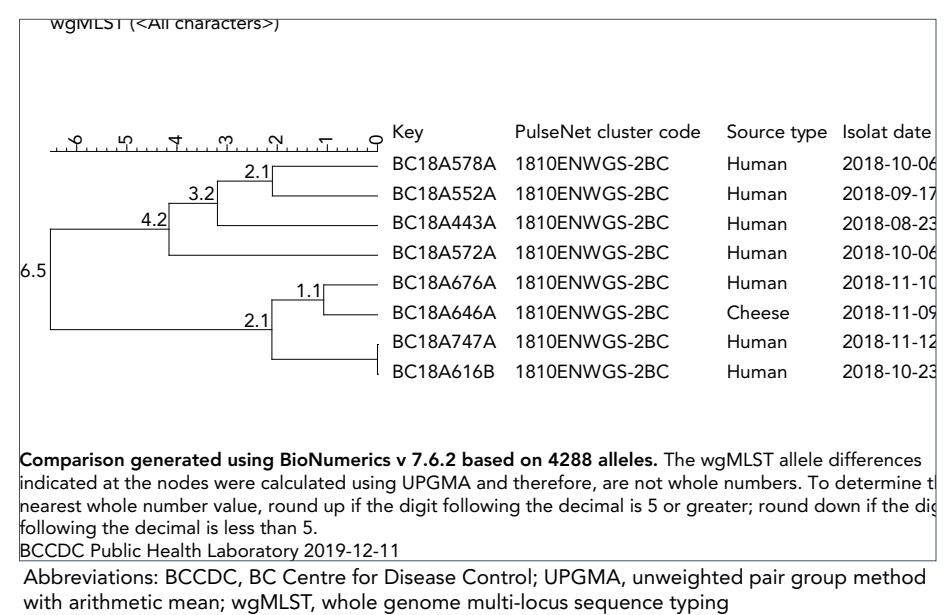


Dairy plant $A$ discontinued production of cheese $A$ on November 9, 2018, and all lots of cheese $A$ at the dairy plant were placed on hold. All lots of cheese $A$ were recalled on November 12 and a public health notice was issued on November 13 (Figure 1). No additional cases occurred after these actions were taken. By March 2019, all the detained cheese had been destroyed.

\section{Discussion}

An investigation of a STEC outbreak involving seven cases was conducted in BC between August and November 2018. The outbreak was associated with the consumption of a raw milk Gouda-like cheese product and was due to raw milk contamination. This STEC outbreak was the second in BC, the third in Canada and the fourth in North America to be caused by raw milk Gouda or Gouda-like cheese since 2002 (12-14). It was the first to be caused by $E$. coli 0121 . This investigation adds further evidence to the series of calls to action by public health professionals to improve control measures in the production of raw milk Gouda and Gouda-like cheeses.

Epidemiologic, laboratory and food safety investigations confirmed raw milk Gouda-like cheese to be the source of this outbreak. All seven outbreak cases reported consuming cheese, with five reporting consuming cheese from the same $B C$ dairy plant and four reporting consuming the same cheese product. A sample of this cheese product tested positive for the same strain of E. coli O121 as the cases. A single batch of this cheese could explain all the illnesses; cheese from this batch was the only one that tested positive for the outbreak strain among the 16 tested and the implicated batch was available to all cases for consumption. All other cheese products and environment swabs tested negative for STEC. Furthermore, the specific cheese product contained no pasteurization and no kill step for the raw protein, which is a known vehicle for transmission of pathogens. Therefore, contaminated raw milk is believed to be the source of cheese contamination. Cattle are the primary reservoir of STEC, and infected cows are asymptomatic and shed sporadically $(22,23)$.

This outbreak was solved and controlled very rapidly. The outbreak investigation was launched on November 1. The reporting of cheese consumption by four cases on November 5 led to the hypothesis that cheese was the source. Following re-interviews, cheese A was hypothesized as the source of the outbreak on November 9. The food safety investigation started on November 9, a cheese A sample tested positive on November 11 and the product was recalled on November 12. The duration of the outbreak investigation was 11 days, which is much shorter than the median of 39 days for BC outbreak investigations (24). The rapidity of the investigation and actions taken by investigators and the dairy plant minimized the impact on the population.
Dairy plant A was compliant with current Canadian regulatory requirements and aged its raw milk Gouda-like cheese for over 60 days (25). Nevertheless, three separate batches were found to be contaminated with STEC.

This is the third reported STEC outbreak caused by raw milk Gouda or Gouda-like cheese aged longer than the 60-day minimum $(13,14,26)$. Several studies have shown that 60 days of aging is insufficient to inactivate pathogenic bacteria in Gouda cheese $(12,15,17,27)$. Gouda and Gouda-like cheese production involves a curd-washing step to reduce the amount of lactose in the cheese curds. The combined effects from the addition of hot water to the curds dilutes out the lactose in the whey, shrinks the curds to expel moisture and creates an osmotic gradient across the curd membrane to draw out lactose while reabsorbing water. This new state decreases the formation of lactic acid, thus increasing the $\mathrm{pH}$ and moisture of the curd. Higher $\mathrm{pH}$ and moisture increase the risk of survival and growth of microbial contaminants (28).

This outbreak provides further evidence of the inherent risk of raw milk Gouda and Gouda-like cheeses. This is the fourth call to strengthen the regulatory requirements for such cheeses. At a minimum, we recommend enhancing milk and cheese-processing controls and increasing consumer awareness. As a result of this outbreak, we recommend the thermization of raw milk prior to production of Gouda and Gouda-like cheeses to decrease the risk of microbial contamination yet retain the appeal of unpasteurized milk cheese. Thermization of raw milk at $64.4^{\circ} \mathrm{C}$ for 17.5 seconds can achieve at least a five-log reduction of E. coli O157:H7 (29-31). We also recommend mandatory product labelling to indicate whether raw, unpasteurized or pasteurized milk is used to increase consumer awareness and support informed decision-making. Dairy plant A now uses pasteurized milk, discontinued the curd-washing step and standardized the heating step to prepare the spice mixes, leading to a lower-risk cheese.

\section{Limitations}

There are several limitations in this investigation. Neither the health of the cows on the farmstead nor the quality of the milk were examined during the outbreak. Therefore it was not confirm whether E. coli 0121 stx2 was present in the herd at the time of the outbreak. In addition, the traceability of the cheese from the manufacturer to retailers was limited by poor records. Lastly, no raw Gouda or Gouda-like cheese exposure data were available for the healthy population controls to allow a direct comparison to outbreak cases.

\section{Conclusion}

This outbreak provides further evidence that raw milk Gouda and Gouda-like cheese processed according to regulations in North America is at risk of containing STEC, which contributes to foodborne illness. It is recommended implementing additional control measures for raw milk Gouda and Gouda-like cheese production to minimize the risk to the public. 


\section{Authors' statement}

EB - Analyzed and interpreted the data and drafted the article MT - Conceptualized the work, analyzed and interpreted the data and revised the article

JS - Contributed to the acquisition of the data for the work and revised the article

SS - Contributed to the acquisition of the data for the work, drafted certain sections and revised the article

AT - Contributed to the acquisition of the data for the work, drafted certain sections and revised the article

$\mathrm{PH}$ - Conceptualized the work, interpreted the data and revised the article

$\mathrm{LH}$ - Contributed to the acquisition and interpretation of the data and revised the article

LJ - Contributed to the acquisition and interpretation of the data drafted certain sections and revised the article

$\mathrm{SM}$ - Contributed to the acquisition, analysis and interpretation of the work and revised the article

CT - Contributed to the acquisition, analysis and interpretation of the work, drafted certain sections and revised the article EG - Conceptualized the work, interpreted the data, drafted certain section and revised the article

\section{Competing interests}

None.

\section{Acknowledgements}

The authors wish to acknowledge the contributions of local laboratories in British Columbia (BC), local health authority Environmental Health Officers and Medical Health Officers, and Dr. J Pritchard, Chief Veterinary Officer of BC.

\section{Funding}

The authors do not have any funding to declare.

The content and view expressed in this article are those of the authors and do not necessarily reflect those of the Government of Canada.

\section{References}

1. Valilis E, Ramsey A, Sidiq S, DuPont HL. Non-O157 Shiga toxin-producing Escherichia coli-A poorly appreciated enteric pathogen: systematic review. Int J Infect Dis 2018;76:82-7. DOI PubMed

2. Ochoa TJ, Cleary TG. Epidemiology and spectrum of disease of Escherichia coli O157. Curr Opin Infect Dis 2003;16(3):259-63. DOI PubMed
3. Noftall K, Taylor M, Hoang L, Galanis E. Shiga toxin-producing Escherichia coli in British Columbia, 2011-2017: analysis to inform exclusion guidelines. Can Commun Dis Rep 2019;45(9):238-43. DOl PubMed

4. Johnson KE, Thorpe CM, Sears CL. The emerging clinical importance of non-O157 Shiga toxin-producing Escherichia coli. Clin Infect Dis 2006;43(12):1587-95. DOI PubMed

5. Morton V, Cheng JM, Sharma D, Kearney A. Notes from the field: an outbreak of Shiga toxin-producing Escherichia coli O121 infections associated with flour - Canada, 2016-2017. MMWR Morb Mortal Wkly Rep 2017;66(26):705-6. DOI PubMed

6. Crowe SJ, Bottichio L, Shade LN, Whitney BM, Corral N, Melius B, Arends KD, Donovan D, Stone J, Allen K, Rosner J, Beal J, Whitlock L, Blackstock A, Wetherington J, Newberry LA, Schroeder MN, Wagner D, Trees E, Viazis S, Wise ME, Neil KP. Shiga toxin-producing E. coli infections associated with flour. N Engl J Med 2017;377(21):2036-43. DOI PubMed

7. Hedican EB, Medus C, Besser JM, Juni BA, Koziol B, Taylor C, Smith KE. Characteristics of O157 versus non-O157 Shiga toxin-producing Escherichia coli infections in Minnesota, 2000-2006. Clin Infect Dis 2009;49(3):358-64. DOI PubMed

8. Farrokh C, Jordan K, Auvray F, Glass K, Oppegaard H, Raynaud S, Thevenot D, Condron R, De Reu K, Govaris A, Heggum K, Heyndrickx M, Hummerjohann J, Lindsay D, Miszczycha S, Moussiegt S, Verstraete K, Cerf O. Review of Shiga-toxin-producing Escherichia coli (STEC) and their significance in dairy production. Int J Food Microbiol 2013;162(2):190-212. DOI PubMed

9. Robinson TJ, Scheftel JM, Smith KE. Raw milk consumption among patients with non-outbreak-related enteric infections, Minnesota, USA, 2001-2010. Emerg Infect Dis 2014;20(1):38-44. DOI PubMed

10. Denny J, Bhat M, Eckmann K. Outbreak of Escherichia coli O157:H7 associated with raw milk consumption in the Pacific Northwest. Foodborne Pathog Dis 2008;5(3):321-8. DOl PubMed

11. Keene WE, Hedberg K, Herriott DE, Hancock DD, McKay RW, Barrett TJ, Fleming DW. A prolonged outbreak of Escherichia coli O157:H7 infections caused by commercially distributed raw milk. J Infect Dis 1997;176(3):815-8. DOI PubMed

12. McCollum JT, Williams NJ, Beam SW, Cosgrove $S$, Ettestad PJ, Ghosh TS, Kimura AC, Nguyen L, Stroika SG, Vogt RL, Watkins AK, Weiss JR, Williams IT, Cronquist AB. Multistate outbreak of Escherichia coli O157:H7 infections associated with in-store sampling of an aged raw-milk Gouda cheese, 2010. J Food Prot 2012;75(10):1759-65. DOl PubMed 
13. Currie A, Galanis E, Chacon PA, Murray R, Wilcott L, Kirkby P, Honish L, Franklin K, Farber J, Parker R, Shyng S, Sharma D, Tschetter L, Hoang L, Chui L, Pacagnella A, Wong J, Pritchard J, Kerr A, Taylor M, Mah V, Flint J. Investigative Team. Outbreak of Escherichia coli O157:H7 infections linked to aged raw milk Gouda cheese, Canada, 2013. J Food Prot 2018;81(2):325-31. DOI PubMed

14. Honish L, Predy G, Hislop N, Chui L, Kowalewska-Grochowska K, Trottier L, Kreplin C, Zazulak I. An outbreak of E. coli O157:H7 hemorrhagic colitis associated with unpasteurized gouda cheese. Can J Public Health 2005 May-Jun;96(3):182-4. DOI PubMed

15. Gill A, Oudit D. Enumeration of Escherichia coli $O 157$ in outbreak-associated Gouda cheese made with raw milk. J Food Prot 2015;78(9):1733-7. DOI PubMed

16. BC Centre for Disease Control. Escherichia coli: Case definition 2018. Vancouver (BC): BCCDC (accessed 2019-08-28). http://www.bccdc.ca/health-professionals/ clinical-resources/case-definitions/e-coli

17. BC Centre for Disease Control. Shigatoxigenic E. coli case report form. Version date: 2018-06-22. http://www.bccdc.ca/ resource-gallery/Documents/Guidelines\%20and\%20Forms/ Forms/Epid/Enterics/VTEC_FollowupForm.pdf

18. Centre for Food-borne, Environmental and Zoonotic Infectious Diseases. Foodbook report. Guelph (ON): Public Health Agency of Canada; 2015. https://www.canada. ca/en/public-health/services/publications/food-nutrition/ foodbook-report.html

19. Guidelines and Protocols Advisory Committee. BC Ministry of Health Services. Infectious diarrhea - guideline for ordering stool specimens (updated 2009-03-16). https:// www2.gov.bc.ca/assets/gov/health/practitioner-pro/ bc-guidelines/diarrhea.pdf

20. Health Canada. Isolation of Escherichia coli O157:H7/NM from food and environmental surface samples (MFHPB-10). Ottawa (ON): Government of Canada; 2017.

21. National Microbiology Laboratory (NML). Whole genome sequencing (WGS) for PNC Laboratories. Winnipeg (MB): Public Health Agency of Canada; 2016.

22. Venegas-Vargas $C$, Henderson $S$, Khare A, Mosci RE, Lehnert JD, Singh P, Ouellette LM, Norby B, Funk JA, Rust S, Bartlett PC, Grooms D, Manning SD. Factors associated with Shiga toxin-producing Escherichia coli shedding by dairy and beef cattle. Appl Environ Microbiol 2016;82(16):5049-56. DOI PubMed
23. Kulow MJ, Gonzales TK, Pertzborn KM, Dahm J, Miller BA, Park D, Gautam R, Kaspar CW, Ivanek R, Döpfer D. Differences in colonization and shedding patterns after oral challenge of cattle with three Escherichia coli O157:H7 strains. Appl Environ Microbiol 2012;78(22):8045-55. DOI PubMed

24. Fong D, Otterstatter M, Taylor M, Galanis E. Analysis of enteric disease outbreak metrics, British Columbia Centre for Disease Control, 2005-2014. Can Commun Dis Rep 2017;43(1):1-6. DOI PubMed

25. Department of Justice. Food and drug regulations (C.R.C, c 870). Part B: Foods (continued). Division 8: Dairy products (continued). Milk (continued). Ottawa (ON): Government of Canada; 2006 (accessed 2019-12-02). https://laws.justice. gc.ca/eng/regulations/c.r.c.,_c._870/page-44.html

26. Gaulin C, Levac E, Ramsay D, Dion R, Ismaïl J, Gingras S, Lacroix C. Escherichia coli O157:H7 outbreak linked to raw milk cheese in Quebec, Canada: use of exact probability calculation and casecase study approaches to foodborne outbreak investigation. J Food Prot 2012;75(5):812-8. DOI PubMed

27. D'Amico DJ, Druart MJ, Donnelly CW. Behavior of Escherichia coli O157:H7 during the manufacture and aging of Gouda and stirred-curd Cheddar cheeses manufactured from raw milk. J Food Prot 2010;73(12):2217-24. DOI PubMed

28. Scott R. Cheesemaking operations. In: Robinson RK, Wilbey RA, editors. Cheesemaking practice. 3rd ed. The University of Reading, Reading, UK: Springer Science+Business Media, LLC; 1998. p. 165-92.

29. Schlesser JE, Gerdes R, Ravishankar S, Madsen K, Mowbray J, Teo AY. Survival of a five-strain cocktail of Escherichia coli 0157:H7 during the 60-day aging period of cheddar cheese made from unpasteurized milk. J Food Prot 2006;69(5):990-8. DOl PubMed

30. Peng S, Hummerjohann J, Stephan R, Hammer P. Short communication: heat resistance of Escherichia coli strains in raw milk at different subpasteurization conditions. J Dairy Sci 2013;96(6):3543-6. DOI PubMed

31. D'Aoust JY, Park CE, Szabo RA, Todd EC, Emmons DB, McKellar RC. Thermal inactivation of Campylobacter species, Yersinia enterocolitica, and hemorrhagic Escherichia coli O157:H7 in fluid milk. J Dairy Sci 1988;71(12):3230-6. DOI PubMed 